\title{
The spectrum of neoplasms of uterine cervix and their clinico- morphological correlation in tertiary care center in dakshina Karnataka
}

\author{
Shetty T. ${ }^{1}$, Kairanna N. ${ }^{2}$, Singh B.M.K. ${ }^{3}$, Pavithra P. ${ }^{4}$, Singh V.K. ${ }^{5}$ \\ ${ }^{1}$ Dr. Tanvi Shetty, ${ }^{2}$ Dr. Nikitha Kairanna, both authors are Assistant Professor, Department of Pathology, Melaka \\ Manipal Medical College, Manipal Academy of Higher Education, ${ }^{3}$ Dr. Brij Mohan Kumar Singh, Associate Professor, \\ Department of Pathology, Kasturba Medical College, Manipal Academy of Higher Education, ${ }^{4}$ Dr. Pavithra P., Associate \\ Professor, Department of Pathology, Melaka Manipal Medical College, Manipal Campus, Manipal Academy of Higher \\ Education, ${ }^{5}$ Dr. Varun Kumar Singh, Assistant Professor, Department of Pathology, Melaka Manipal Medical College, \\ Manipal Academy of Higher Education, India
}

Corresponding Author: Dr. Brij Mohan Kumar Singh, Associate Professor, Department of Pathology, Kasturba Medical College, Manipal Academy of Higher Education. E-mail: drbrijkumar@gmail.com

\begin{abstract}
Introduction: Cervical carcinoma is one of the leading causes of death among women worldwide. An estimated of 2,30,000 women die annually from cervical cancer, and almost 1,90,000 are from developing countries. It is considered to be the 3rd most common malignancy among women. Materials and Methods: This is a 5 year retrospective study done in the department of pathology, Kasturba medical college, Manipal. Hysterectomy and cervical biopsies are included in this study. Clinical details were obtained from case sheets. Results: 175 cases of cervical neoplasms were studied in total. The patient's age was ranged 21 to 80 years with mean being 50.5 years. Among the commonest complaints was post-menopausal bleeding followed by menorrhagia and intermenstrual spotting. 49\% cases had a growth in the cervix followed by $12 \%$ cases with induration and $10 \%$ cases as polyp in cervix. Among the 175 cases, $14.86 \%$ cases were precursor lesions. Among the malignant cases, squamous cell carcinomas $(61.71 \%)$ were the commonest. Rare tumour includes $2.86 \%$ cases of minimally invasive carcinoma, $1.71 \%$ cases of neuroendocrine carcinoma, and $1.14 \%$ cases each of serous carcinoma. Conclusion: Neoplastic lesions from the uterine cervix comprise of a wide variety of lesions originating from both the epithelial and stromal elements. Among the malignant tumours, squamous cell carcinoma was very common. Hence, a thorough clinical evaluation and post-menopausal health check-ups along with detailed cervical examination and microscopic evaluation is the key towards correct and timely diagnosis of cervical neoplasms.
\end{abstract}

Keywords: Carcinoma, Cervical neoplasms, Post-menopausal bleeding, Squamous cell carcinoma

\section{Introduction}

Uterine cervix carcinoma is the $3^{\text {rd }}$ most common cancer among females worldwide, next to breast and lung carcinoma. With the effectiveness of cytological screening programs, the incidence and mortality of cervix cancer have decreased drastically in developed countries. Studies have shown that more than $80 \%$ of patients dying of cervical carcinoma are from developing countries [1]. Indian council of medical research reports in India found the incidence is $14.42 / 1,00,000$ population with a mortality rate of 2.83/1,00,000 population [2].

Manuscript received: $7^{\text {th }}$ November 2018

Reviewed: $17^{\text {th }}$ November 2018

Author Corrected: $24^{\text {th }}$ November 2018

Accepted for Publication: $29^{\text {th }}$ November 2018
Particularly in South India, carcinoma cervix is the most common form of cancer in females $[1,3]$. The disease is more prevalent in people living in poor living conditions and low-income groups, probably because of lack of hygiene and lack of regular health check-up due to financial constraints.

Prolonged infection by human papillomavirus has been found to be the most important risk factor for developing carcinoma cervix. Immense lack of awareness, low socioeconomic status, parity, early age of marriage, smoking, etc., has also proven to be among the important risk factors. Prognosis mainly depends on the stage of the disease and the time of detection. The 


\section{Original Research Article}

histological variant is also of significance in determining the prognosis. Rare histological subtypes such as adenocarcinoma, small cell carcinoma, clear cell carcinoma, and sarcoma have poor prognosis $[4,5]$.

In this study we have observed the clinical features, demographic features and incidence of cervical malignancies in our tertiary care center and to view the gross findings and the histomorphological distribution of the cases.

\section{Materials and Methods}

- Place of study: The present study was conducted in the department of pathology, Kasturba medical college, Manipal, from December 2012 to December 2017.

- Type of study: Retrospective study, were a total of 175 cases from hysterectomy and cervical biopsies from all age groups were recruited.
- Sampling method: All diagnosed cases, histologically showing cervical neoplasms along with precursor lesions were included in this study. Patients' data comprising of the age, presenting clinical complaints, their menstrual and obstetric history and examination findings were collected from medical case records.

- Exclusion criteria: Non-neoplastic lesions including inflammation and any specific infections were excluded.

- Method: Paraffin embedded sections of 3-4 micron thickness were cut using microtome and stained with hematoxylin and eosin stain and a detailed histological examination was done as per the World Health Organization (WHO) classification of cervical tumors. All the obtained data was analyzed by descriptive analysis and the results are expressed as sum total and in percentages, as well.

\section{Results}

A total of 3,281 hysterectomy and cervical biopsy specimens were received in this 5year study. Among these 3,281 cases, 175 cases showed features of uterine cervix malignancy and precursor lesions as well. The clinical features and morphological details were thoroughly analyzed in these cases. The patient's age ranged from 21 to 80 years and the mean age distribution was 50.5 years. (Table 1) Clinically majority of the patient's presented with irregular bleeding per vagina (103 cases) including post-menopausal bleeding, menorrhagia, intermenstrual spotting and post-coital bleeding. (Table 2) Friable growth in the cervix was the commonest lesion (49\%) seen in the cervix. (Table 3)

Among the 175 cases, 108 cases $(61.71 \%)$ of squamous cell carcinomas were the commonest. Among the rare tumours, there were $5(2.9 \%)$ cases of minimally invasive carcinoma, $3(1.7 \%)$ cases of neuroendocrine carcinoma, $2(1.14 \%)$ cases each of serous carcinoma, adenosquamous cell carcinoma and poorly differentiated carcinoma. The remaining tumors were adenobasaloid carcinoma, lymphoepithelial like carcinoma, carcinosarcoma and colloid carcinoma accounting for one case each. (Table 1)

Table-1: Distribution of cervical neoplasm with reference to age

\begin{tabular}{|c|c|c|c|c|c|c|c|c|c|c|c|c|c|c|c|c|}
\hline 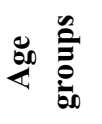 & $\bar{Z}$ & 文 & 文 & U & ¿ & $\stackrel{\infty}{2}$ & 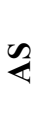 & $\frac{1}{Z}$ & $\exists$ & $\sqrt{2}$ & $\bar{\Sigma}$ & 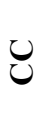 & $\tilde{U}$ & $\hat{\mathrm{a}}$ & U & 包 \\
\hline $21-30$ & 1 & - & & 1 & - & - & - & - & - & - & - & - & - & - & - & 2 \\
\hline $31-40$ & - & 2 & 1 & 14 & 4 & - & - & - & - & 1 & 2 & - & - & 1 & - & 25 \\
\hline $41-50$ & 2 & 3 & 1 & 32 & 9 & - & - & - & - & - & - & 1 & - & - & 2 & 50 \\
\hline $51-60$ & 3 & 7 & 0 & 28 & 5 & - & 2 & 2 & - & - & 1 & - & 1 & - & - & 49 \\
\hline $61-70$ & 1 & 4 & 1 & 21 & 4 & 1 & - & - & 1 & - & - & - & - & 1 & - & 34 \\
\hline $71-80$ & - & - & - & 9 & - & - & - & 1 & - & - & 2 & - & - & - & - & 12 \\
\hline$>80$ & - & - & - & 3 & - & - & - & - & - & - & - & - & - & - & - & 3 \\
\hline Total & 7 & 16 & 3 & 109 & 22 & 1 & 2 & 3 & 1 & 1 & 5 & 1 & 1 & 1 & 2 & 175 \\
\hline
\end{tabular}

Table 1: CIN: cervical in situ neoplasm, SCC: squamous cell carcinoma, ADC: adenocarcinoma, ABS: adenobasaloid carcinoma, AS: adenosquamous, NE: neuroendocrine, LL: lymphoepithelial like carcinoma, ST: stromal tumour, MI: minimally invasive, CC: colloid carcinoma, CS: carcinosarcoma, PD: poorly differentiated, SC: serous carcinoma. 


\section{Original Research Article}

Table-2: Distribution of presenting symptoms

\begin{tabular}{|c|c|c|}
\hline Clinical features & & No. of cases \\
\hline Bleeding & Post-menopausal & 41 \\
& Menorrhagia & 32 \\
& Intermenstrual spotting & 24 \\
& Post-coital bleeding & 6 \\
\hline Vaginal discharge & White discharge & 46 \\
& Blood stained & 22 \\
\hline Pain abdomen & & 68 \\
\hline Urinary disturbance & & 12 \\
\hline Mass per vaginum & & 23 \\
\hline Asymptomatic & & 12 \\
\hline
\end{tabular}

Table-3: Distribution of type of lesion in the cervix.

\begin{tabular}{|c|c|}
\hline Type of lesion & n (\%) \\
\hline Growth & $88(51)$ \\
\hline Polyp & $17(11)$ \\
\hline Induration & $16(09)$ \\
\hline Erosion & $20(11)$ \\
\hline No lesion & $20(11)$ \\
\hline No data & $14(08)$ \\
\hline
\end{tabular}

Table-4: Distribution of cervical intraepithelial neoplasm (CIN)

\begin{tabular}{|c|c|c|c|}
\hline Age & CIN I & CIN II & CIN III \\
\hline $21-30$ & 1 & 1 & - \\
\hline $31-40$ & - & 2 & 1 \\
\hline $41-50$ & 2 & 3 & 1 \\
\hline $51-60$ & 3 & 7 & - \\
\hline $61-70$ & 1 & 3 & 1 \\
\hline
\end{tabular}

Among the 175 cases, $85.14 \%$ cases were malignant and the remaining $14.86 \%$ cases were precursor lesions (Cervical intraepithelial neoplasia (CIN) - I, II, III). There was a total of 26 pre-malignant lesions comprising of 7 cases of CIN-I, 16 cases of CIN-II and 3 cases of CIN-III (Table 4 ).

\section{Discussion}

The present study is conducted with an aim to understand the spectrum of cervical neoplasm in dakshina Karnataka. Data were analyzed to know the relative frequency of different cervical lesions. World health organization reports that cervical carcinoma has an estimated 570,000 new cases in 2018 representing $6.6 \%$ of all female cancers [7]. The various risk factors for carcinoma cervix includes age at first intercourse, increased parity, multiple sex partners, racial factors, socio-economic status, smoking, oral contraceptives etc.

The most common cause of mortality in females all over the world is cervical neoplasms and it is more common in developing countries. Approximately $2,30,000$ women die in a year from cervical carcinoma and over $1,90,000$ of those are from developing countries [1].
According to literature, cervical carcinoma, is supposed to be a preventable disease as it can be detected in its pre-invasive stage by pap smears followed by appropriate treatment. The incidence of cervical carcinoma has considerably decreased due to effective implementation of screening procedure and public awareness. Rural India has higher incidence of carcinoma cervix due to varied reasons like, low socioeconomic status, lack of awareness, early age at marriage, etc. $[3,6]$.

The cases ranged from ages of 21-80 years with mean age of presentation being 50.5 years. In the present study maximum cases was contributed by the age group of 41-50 years (28\%) which was in accordance to studies done by Krishnappa et al. [1], Pradhan et al.[4], Shruthi et al [6], Fotra et al.[8], Sinha et al. [9] and 


\section{Original Research Article}

Jashamy KA et al [10]. Post-menopausal bleeding was found to be the most common clinical complaint followed by per vaginal discharge which was also seen in studies done by Krishnappa et al. [1], Shruthi et al [6], Das et al.[11], Sinha et al [9]. 38.86\% patients presented with pain abdomen which was similar to studies done by Usha et al. [12]. and Krishnappa et al [1], who reported $31.03 \%$ and $21.3 \%$ cases respectively.

In our study, incidence of CIN II cases were more as compared to CIN I and CIN III. Also, it was noticed that these precursor lesions were more in the $4^{\text {th }}$ and early $5^{\text {th }}$ decades, while malignancies were common in late $5^{\text {th }}$ decade. This helps in emphasizing that early screening of these lesions and awareness regarding their importance is a priority among young adults.

Squamous cell carcinoma (SCC) and adenocarcinoma were among the commonest malignancies diagnosed and accounted for $61.71 \%$ of SCC cases and among the least common were adenosquamous carcinoma (1.14\%). This distribution was similar to the findings stated by Krishnappa et al. [1], Shingleton et al [13], Jeong et al. [14], Alfsen et al [15], and Galic et al [16]. The second most common epithelial neoplasm with 22 cases was adenocarcinoma which had endocervical variant $(22.6 \%)$ and villoglandular variant $(18.1 \%)$, which is comparable to data projected by Alfsen et al. [15].

There was only one case reported as carcinosarcoma $(0.57 \%)$, similar incidence was reported by Krishnappa et al. [1], Solapurkar et al. [17]. There were 5 cases of minimally invasive SCC which accounted for $2.9 \%$ of cases which was closer to the percentages obtained by Solapurkar et al [17].

Friable growth in the cervix was the commonest lesion seen in $49 \%$ cases, followed by erosion (12\%) and cervical polyp (10\%) and ulcer $(3 \%)$ were also seen. $11 \%$ cases had no observable lesion in the cervix.

Human papilloma virus (HPV) has been linked to many benign and malignant lesions of the cervix ranging from innocuous condyloma acuminate to invasive carcinoma, the most common being type 6 and 11 [18]. This infection is known to be transmitted by veneral route and has the predilection for the metaplastic squamous epithelium.

\section{Conclusion}

It has been estimated that in an average woman in the 4 th decade has $2 \%$ chance of developing cervical cancer. Almost $50 \%$ of death from cervical carcinoma occurs in the middle-aged women. Since this age group constitutes major working population, not only on the mortality, cervical cancer has major impact on the socioeconomic status of the families [4].

However, women in their 20's to 80's, which comprise of a wide range, are seen affected and they may present with a wide variety of clinical signs and symptoms from being asymptomatic to any emergency condition.

Globally cervical carcinoma is the $3^{\text {rd }}$ most common malignancy among women with a very wide variety of incidence among them. It is very common in developing countries like India, due to reasons like reduced awareness and poverty among majority of the population. Patients are sometimes asymptomatic but, on most episodes, present with chief complaints of bleeding per vagina, vaginal discharge and other nonspecific symptoms. In our study the mean age of presentation was 50.5 years and most of the women were multiparous in their $4^{\text {th }}$ or $5^{\text {th }}$ decade.

The precursor lesions like CIN I, II and III were found in the $3-4^{\text {th }}$ decade as compared to older age groups. With the help of these findings, it is evident that women should be screened at regular intervals during the years when they are sexually active and thorough examination should be performed for women who come with complaints of bleeding per vagina or any vaginal discharge.

The limitation of this study is the evaluation of prevalence of HPV infection which could have been done with the help of p16 on immunohistochemistry (IHC) marker, to consider the role of HPV in the aetiology of the reported cervical neoplasms in the present study.

\section{Author contribution detail:}

Concept and design: Dr. Tanvi Shetty, Dr. Brij Mohan Kumar Singh.

Definition of intellectual content: Dr. Brij Mohan Kumar Singh

Literature search: Dr. Nikita kairanna, Dr. Varun Kumar Singh, Dr. Pavithra P

Manuscript preparation: Dr. Tanvi Shetty, Dr. Nikita Kairanna

Manuscript editing and manuscript review: Dr. Brij Mohan Kumar Singh, Dr. Pavithra P

Findings: Nil; Conflict of Interest: None initiated Permission from IRB: Yes 
Original Research Article

\section{References}

1. Krishnappa C, Kanabur DR, Dinesh CU. Clinicomorphological Spectrum of Neoplasms of Uterine Cervix in a Tertiary Care Center in North Karnataka, South India. Int J Sci Stud 2016;4(2):6-12.

2. Park K. Park's Textbook of Preventive and Social Medicine. $21^{\text {st }}$ ed. India: M/S Banarasidas Bhanot; 2011.

3. Tavassoli AF, Devilee P. WHO Classification of Tumors, Pathology and Genetics - Tumors of The Breast and Female Genital Organs. Lyon, France: IARC Press; 2003 pp. 259-90

4. Pradhan B, Pradhan SB, Mital VP. Correlation of PAP smear findings with clinical findings and cervical biopsy. Kathmandu Univ Med J (KUMJ). 2007 OctDec; 5(4): 461-7.

5. Vincent VH, Claire B, Georges V, Gabor C, Mark DR, Guy S, et al. Prognostic Value of Histopathology and Trends in Cervical Cancer: A SEER Population Study. Vol. 7. Biomed Center Springer Link: BMC Cancer; 2007.

6. Shruthi PS, Kalyani R, Kai LJ, et al. Clinicopathological correlation of cervical carcinoma: a tertiary hospital based study. Asian Pac J Cancer Prev. 2014; 15 (4):1671-4.

7. World health organization 2018, http:// www.who. int/cancer/prevention/diagnosis-screening/cervicalcancer/en/

8. Fotra R, Gupta S, Gupta S. Sociodemographic risk factors for cervical cancer in Jammu region of $\mathrm{J}$ and $\mathrm{K}$ state of India first ever report from Jammu. Indian J Sci Res 2014;9:105-10.

9. Sinha P, Rekha PR, Subramaniam PM, Konapur PG, Thamilselvi R, Jyothi BL. A Clinicomorphological study of carcinoma cervix. Nat J Basic Med Sci 2011;2:2-7.
10. Al-Jashamy K, Al-Naggar RA, San P, et al. Histopathological findings for cervical lesions in Malaysian women. Asian Pac J Cancer Prev. 2009; 10(6):1159-62.

11. Das RK et al. Cancer cervix in Assam. An etiological analysis of 250 cases. J obstet gynecol India. 1969, p11-16.

12. Usha, Narang BR, Tiwari $P$, Asthana AK, Jaiswal V. A clinico morphological study of benign tumors of cervix. J Obstet Gynecol India 1992;1:422-8.

13. Shingleton HM, Bell MC, Fremgen A, et al. Is there really a difference in survival of women with squamous cell carcinoma, adenocarcinoma, and adenosquamous cell carcinoma of the cervix? Cancer. 1995 Nov 15;76 (10 Suppl):1948-55.

14. Jeong BK, Choi DH, Huh SJ, et al. The role of squamous cell carcinoma antigen as a prognostic and predictive factor in carcinoma of uterine cervix. Radiat Oncol J. 2011 Sep;29 (3):191-8. doi: 10.3857/roj. 2011. 29.3.191. Epub 2011 Sep 30.

15. Alfsen GC, Kristensen GB, Skovlund E, et al. Histologic subtype has minor importance for overall survival in patients with adenocarcinoma of the uterine cervix: a population-based study of prognostic factors in 505 patients with nonsquamous cell carcinomas of the cervix. Cancer. 2001 Nov 1;92(9):2471-83.

16. Galic V, Herzog TJ, Lewin SN, et al. Prognostic significance of adenocarcinoma histology in women with cervical cancer. Gynecol Oncol. 2012 May;125 (2): 287-91. doi: 10.1016/j.ygyno.2012.01.012. Epub 2012 Jan 18.

17. Solapurkar ML. Histopathology of uterine cervix in Malignant and benign lesions. J Obstet Gynecol India 1985;35:933

18. Rao KB. Evolution of obstetrics, gynaecology and family planning in India. Indian J Hist Med. 1974 Jun;19(1):15-33.

\section{How to cite this article?}

Shetty T, Kairanna N., Singh B.M.K., Pavithra P., Singh V.K. The spectrum of neoplasms of uterine cervix and their clinico-morphological correlation in tertiary care center in dakshina Karnataka. Trop J Path Micro 2018;4(7):486490.doi:10.17511/jopm.2018.i07.02. 